\title{
EMPLOYEE ENGAGEMENT AND ITS DRIVERS IN ITES ORGANIZATION
}

\section{MANISH BHALLA}

Jagannath University, Jaipur, Rajasthan, India

\begin{abstract}
The collective loss to Indian IT organization due to regularly losing its employees is mind boggling. In the last couple of years, companies have realized that wages are important to employees, but compensation alone cannot motivate the highly skilled and experienced workforce. The HR managers are laying the road map for the right working conditions which would inspire the employees to be engaged, give their best, go their extra mile and persist in the face of difficulties. The challenge faced by the management is therefore not just in retaining the talented employees, but in engaging them. As organizations go worldwide and become more dependent on technology in a virtual company, there is a greater need to connect and engage with employees to provide them with an organizational identity. The Indian Information Technology Enabled Services (ITES)-Business Process Outsourcing (BPO) industry has rapidly opened up, expanded, matured and with a wave of consolidation has scripted new initiatives. In this era of globalization, every organization comprises of work place spreading over different culture, different personality, diverse age and experience, multiple aspirations and needs.

KEYWORDS: Indian IT Organization, Motivation, Key Drivers to Connect and Engage, Employee Retention \& Gallup's Q12 measures
\end{abstract}

Received: Dec 12, 2017; Accepted: Jan 02, 2018; Published: Jan 12, 2018; Paper Id.: IJHRMRFEB20182

\section{INTRODUCTION}

Today's organization requires different access to training and career opportunities, work/life balance and empowerment to foster a culture of engagement. HR leads the way by designing measure and by evaluating proactive workplace policies and practices that could help in attracting and retaining talent with skills and competencies necessary for growth and sustainability. As companies face this environment the ability to attract, engage, develop and retain talent will become increasing important (Lockwood, 2007). Employee engagement policies of the organization makes employee feel that the organization cares for his/her concerns about personal welfare and congenial work environment which enhances his/her well-being making him/ her belong to the organization termed as loyalty. Employee loyalty must be earned through a culture of respect and integrity, and learning and development (Lockwood, 2007).

Employee engagement has become the Human Resources theme of the moment, many progressive organizations, are using employee engagement strategies as their major competitive edge in the current global competitive environment. As an aspect of HR it is becoming more and more critical to the success of businesses, especially in environments where there is robust competition for talent, expertise and experience.Understanding employee needs must, thus, occupy the centre stage not only for the HR team but also the immediate bosses.Today's organizations want their employees to be strategic, proactive, initiators, energetic and effectively engaged with their work and organization. On the other hand all employees are individual human beings and they have their needs, aspirations, drives and capabilities at varying degrees of intensity. Most of these remain unexpressed and the 
employer is left with no other option but to understand these needs, aspirations, capabilities and develop a system that creates an environment which is beneficial to all the stakeholders.Kahn (1990) referred to engagement as a situation where people express themselves physically, cognitively and emotionally during work role performance. "Engagement is the state in which individual are emotionally and intellectually committed to the organization as measured by three primary behaviors: say, stay and strive".The behavioral factor is the value added component reflected in the amount of effort employees put into their work (Lockwood, 2007).

Gallup defines Engaged employees are those who work with a passion and feel profound connection to their company and drive innovation and move the organization forward.Engagement is influenced by many factors: workplace culture, communication, managerial styles, trust and respect (Lockwood, 2007).The impact of an 'engaged' workforce as opposed to an 'unengaged' one is dramatic and therefore employee engagement at all levels must not only be encouraged but also rewarded.Thus the HR coined the term "Employee Engagement" when the organization takes measures for an engaged workforce, the profit and the productivity spikes. Engagement at work was conceptualized by Kahn as the 'harnessing of organizational members' selves to their work.Thus Employee Engagement is a measure that determines the association of a person with the organization.Employee engagement isn't a one-dimensional concept, something that can be increased simply by sending out a survey or instituting a program. Instead, organizations that are successful at increasing employee engagement realize that it requires culture change.Engaged employees are fully involved in, and enthusiastic about their work. They care about the future of the company and are willing to invest the discretionary effort - exceeding duty's call - to see that the organization succeeds.A successful employee engagement helps to create a community at the workplace and not just employees. The added advantage of creating or working from an employee engagement baseline, is that we can measure the success of HR programs, allocating more resources to initiatives that are working and improving those activities that are not showing expected results.

\section{RESEARCH OBJECTIVES}

The prime objective of the research paper is to explore the employee engagement from the lenses of individual differences and understanding it as a concept and its drivers that defines business success. The incidental objectives of the present research are as under:

- To define engagement and establishits nature from relevant literature.

- To identify aspects of working life that impact most strongly on engagement, and could be seen as drivers.

- Development and testing of an engagement indicator from the attitude statements in the IT organizations.

- To establish differences in engagement levels by employee group using demographic variables at work.

- To suggest policy makers and HR specialists implement changes in their organizational approaches for making their organizations more employable and employee engaging.

\section{METHODOLOGY}

The study is based on both primary and secondary data. The primary data is collected from the IT sector employees in NCR region directly with the help of a structured questionnaire. Secondary data is collected from journals and websites. 


\section{Need and Rationale}

The research methodology is exploratory as the researcher is trying to find out what engagement is along with its drivers that affect employee engagement and the most important ones that HR managers need to look at to improve employee engagement levels within their organization. Employee engagement is at or near the top of most surveys that cover the concerns of HR Managers. The purpose of the research is to administer a survey that would assess the strengths and the weaknesses in the employee engagement of IT Companies. The data will provide an aid in decision making and establish measurers for evaluating change in the organization over time. The research paper not only explores the significance of the drivers for overall employee engagement but individual demographic factors are also subjected to statistical introspection. The research paper explores the individual differences across five parameters as gender, age, level, experience and educational qualifications. Tabulated data has been analyzed with the help of descriptive statistics like frequency counts and percentages. Significant variations are observed across employees of various gender, age, level, experience and educational qualifications.

\section{Construction of Questionnaire}

Gallup's Q12 measures have been used as a method of measuring employee engagement at a point in time. These twelve questions measure the core elements needed to attract, focus, keep the most talented employees, and measure the strength of the workplace (Buckingham \& Coffman, 1999). In the Gallup survey they develop measures of employee perceptions, and focused on the important human resource issues on which managers can develop specific action plans. Gallup used these questions to find to a few questions that would truly measure the strong workplace. These twelve questions do not capture everything you may want to know about the workplace, but they capture the most information and the most important information. Gallup was searching for those special questions where the most engaged employees, those who are loyal and productive answered positively and everyone else the average performers answered neutrally or negatively. The data has been obtained from the two IT companies in NCR region. The review of literature and the pilot study formed the base for the development of Employee Engagement Scale. It comprises of 12 factors based on statements developed by Gallup which are Role Clarity, Adequate Resources, Job Opportunity, Recognition, Cooperation, Development, Inclusiveness, Belongingness, Teamwork, Relationships, Feedback and Learning.

\section{Sampling Size and Fieldwork}

The present survey has been carried out in NCR by collecting 75 samples from HCL and another 75 samples from CSC of employees who work at entry level in the company with the help of structured questionnaire. Sample was selected at random by adopting convenient sampling technique. This sample was selected for the study because they are the individuals that have the most influence on the employee engagement practices now being implemented in the organization.

\section{MEANING, CONCEPT AND DRIVERS OF EMPLOYEE ENGAGEMENT}

\section{Meaning and Concept}

The purpose of this section is to review what employee engagement means in the literature in order to identify if a clear and common idea of what engagement is can be drawn out. 
Employee Engagement is a measurable degree of an employee's positive or negative emotional attachment to their job, colleagues and organization that profoundly influences their willingness to learn and perform at work. Positive affectivity echoes existing definitions of employee engagement and thus represents a central component of the engagement construct. The main reason behind the popularity of employee engagement is that it has positive consequences for organizations. There is a general belief that there is a connection between employee engagement as an individual level construct and business results (Harter et al. 2002).According to the Hay Group (2001), engagement is comprised of two components: Commitment - affective attachment to and intention to remain with an organization and Discretionary Effort - the willingness to go above and beyond formal job requirements. Measure (2004) defines engagement as a level of commitment and involvement of employees towards their organization and its values by speaking positively about the organization, coworkers, potential employees and customers, having strong desire to be the member of organization and exerting extra effort to contribute to organization success.

Blizzard (2004) Gallup suggested that engaged employees are 'psychologically committed to their work, go above and beyond their basic job expectations, and want to play a key role in fulfilling the mission of their organizations', whilst disengaged employees were said to be 'uninvolved and unenthusiastic about their jobs and love to tell others how bad things are'. Baumruk and Marusarz (2004) Hewitt Associates defines engagement as 'the energy, passion or "fire in the belly" employees have for their employer or more specifically what their employer is trying to achieve in the market'. Hewitt Associates also suggest that engaged employee stay, say and drive. In other words, engaged employees 'have an intense desire to be members of the organization ... are passionate advocates for their workplace ... they refer potential employees and customers ... they go beyond what is minimally required to produce extraordinary service and results for customers and colleagues'.Lockwood (2007) states that employee engagement is the extent to which employees commit to something or someone in the organization, those who are loyal and productive.Mercer (2007) defines engagement as 'a state of mind in which employees feel a vested interest in the company's success and are both willing and motivated to perform to levels that exceed the stated job requirements. It is the result of how employees feel about the work experience - the organization, its leaders, the work and the work environment'. Truss et al (2009) 'Engagement is about creating opportunities for employees to connect with their colleagues, managers and wider organization. It is also about creating an environment where employees are motivated to want to connect with their work and really care about doing a good job ... It is a concept that places flexibility, change and continuous improvement at the heart of what it means to be an employee and an employer in a twenty first century workplace."

\section{Drivers of Employee Engagement}

This section discusses the drivers of employee engagement throughout the literature resulting in highlighting the key driver by which an engaged workforce can be identified. Here drivers given by a number of experts have been combined together to present a comprehensive and holistic picture of employee engagement.

In the literature on employee engagement, one frequently comes across the term ${ }^{\text {ee }}$ drivers ${ }^{\text {ee }}$ of engagement, which has been popularized by consulting firms as well as HR practitioners. A driver is something that drives. For example, any part of a machine that communicates motion to another part is called a driver. Persons who use the term "driverse to explain variation in employee engagement across business units have done so entirely on the basis of observed positive relationship. When the engagement initiatives are framed, it becomes pertinent to focus on the driver which would 
influence engagement to the highest extent. By managing the drivers, such as communication, performance clarity and feedback, organizational culture, rewards and recognition, relationships with managers and peers, career development opportunities and knowledge of the organization's goals and vision organization can effectively manage engagement levels of its employees. After a wide range of study, the Institute of Employment Studies have found various drivers for engagement. Pay and benefits, equal opportunities, feeling valued and involved, stress and work pressure, career development, management, colleagues, feedback, communication training and development are considered the important drivers of a culture of engagement. As a HR manager, one needs to ensure that the key drivers are actively used for better engagement.

There are many drivers in employee engagement and they differ from company to company. In order for engagement strategy to be successful, it must be tailored to the objectives and culture of each organization. The culture of an organization should be supplementary to create employees engaged and which would upsurge the employee performance, which is key criterion for the Companies growth.Robinson et al (2004) state that drivers of engagement can be a useful pointer to organizations towards those aspects of working life that require serious attention if engagement levels are to be maintained or improved. It is clear that the organizationhas a responsibility to lead engagement, and there are several key areas the organization can address to encourage engagement among its employees. Leadership, effective management, open, two-way communication, pay and benefits, fair and equal treatment, employing the 'right' workforce, career development and training, working hours, and health and safety are all aspects of the work environment that organizations can control and influence and have been found to impact upon engagement levels. However, there is no 'one size fits all' model of engagement, and different employees will place different emphasis on the extent to which they value each of these drivers in return for 'going the extra mile'.

Kahn (1990) found that a person's level of engagement was a function of the experience of three psychological conditions: psychological meaningfulness, psychological safety, and psychological availability. Kahn's three conditions seem especially relevant and important for newcomers for understanding how to engage. He found that work that is experienced as challenging, clearly delineated, varied, creative, and autonomous is most likely to be associated with the experience of psychological meaningfulness. He also found that psychological safety was influenced by interpersonal relationships, group and intergroup dynamics, management styles and processes, and organizational norms. Lastly, he found that psychological availability was negatively influenced by depletion of physical, emotional and psychological resources required to invest one's self in the performance of the role. Development Dimensions International (DDI, 2005) states that a manager must do five things to create a highly engaged workforce. They are: align efforts with strategy, empower, promote and encourage teamwork and collaboration, help people grow \& develop and provide support and recognition where appropriate.

Cropley (2005) says that the function of an organization's culture is to define boundaries, convey a sense of identity, and help generate commitment to something larger, enhance stability, social system and act as a mechanism to guide and shape attitude and behavior of employees. Employee wellbeing will lead to their loyalty in long run and engage them with the organizations.Seijts, Gerard H.; Crim, Dan (2006) offers several avenues for action which is summarized as the Ten C's of employee engagement namely connect, career, clarity, convey, congratulate, contribute, control and collaborate, credibility \& confidence. CIPD (2006) on the basis of its survey of 2000 employees from across Great Britain indicates that communication is the top priority to lead employees to engagement. The report singles out having the 
opportunity to feed their views and opinions upwards as the most important driver of people's engagement. The report also identifies the importance of being kept informed about what is going on in the organization. According to Penna research report (2007) meaning at work has the potential to be valuable way of bringing employers and employees closer together to the benefit of both where employees experience a sense of community, the space to be themselves and the opportunity to make a contribution, they find meaning. Employees want to work in the organizations in which they find meaning at work. Penna (2007) researchers have also come up with a new model they called "Hierarchy of engagement" which resembles Maslow's need hierarchy model. In the bottom line there are basic needs of pay and benefits. Once an employee satisfied these needs, then the employee looks to development opportunities, the possibility for promotion and then leadership style will be introduced to the mix in the model.

Lockwood, Nancy R (2007) states that employee engagement is a key business driver for organizational success.High levels of engagement in domestic and global firms promote retention of talent, foster customer loyalty and improve organizational performance and stakeholder value. A complex concept, engagement is influenced by many factors--from workplace culture, organizational communication and managerial styles to trust and respect, leadershipand company reputation.Bakker \&Demerouti, (2008) suggest that feedback also promotes engagement because it fosters learning, which increases job competence and the likelihood of being successful in achieving one's work goals.Demerouti and Cropanzano (2010) argued that job resources are hypothetical antecedents of engagement, so the current study focuses on job resources in the form of managerial support, training, and development opportunities.Solomon Markos and M. SandhyaSridevi (2010), In order to have engaged employees in any organization, managers suggested looking at ten points. Start it on day one, Start it from the top, Enhance employee engagement through two-way communication, give satisfactory opportunities for development and advancement. Organizations should ensure that employees have everything they need to do their jobs, Give employees appropriate training, Have strong feedback system, Incentives have a part to play, Build a distinctive corporate culture, Focus on top-performing employees.

Dr. YasminJanjhua (2011), Employee Engagement: A Study of HPSEB Employees the results showed that job characteristics contribute to job engagement, and organizational engagement. If the employees feel that their jobs provided variety, freedom, identity and proper feedback the employees get more engrossed and engaged in their work thereby leading to more quality, productivity and efficiency. Perceived organizational support was significantly positively related to job engagement and organizational engagement.Kinjal Bhatt (2012), while conducting a case study at GNFC on Employee engagement: a tool to achieve sustainable growth, noted that Employee Engagement in an organization can definitely enhance organization's performance, productivity, pride and prestige. Employee Engagement depends on one's professional knowledge, concern for job and motivation from superiors. In GNFC she found good working environment, sharing and openness to share views, training and development, good pay structure and perks, etc. which was responsible for high ratio of employee engagement.According to Swanlatha and Suresh Krishna (2013) there are three factors which foster employee engagement and productivity - Achievement: The vast majority of employees want to achieve something important and meaningful at work. They want to learn and develop their skills and capabilities and they want to be rewarded and recognized for their efforts; Camaraderie: Employees enjoy working productively with others while developing healthy interpersonal relationships. How manager interact with his/her team is very important in motivating employees to go above and beyond; Equity: Employees want to be treated fairly when it comes to pay and benefits, daily treatment given to them and physical and psychological safety. When these basic needs are met, employees were highly engaged and enthusiastic at work. 
Alfes Et Al. (2013) in their research paper titled 'Linking Perceived Supervisor Support, Perceived HRM Practices and Individual Performance: The Mediating Role of Employee Engagement' examined data from over 2,000 employees of a recycling and waste management company and found results indicating that line manager behavior and perceived organizational practices drove employee engagement, which in turn was strongly linked to innovative work behavior.Jenkins and Delbridge (2013) in their research paper titled 'Context matters: examining 'soft' and 'hard' approaches to employee engagement in two workplaces' proposed that it was possible to distinguish between hard and soft management approaches to enhancing engagement. In their case studies of two companies, one adopted a soft approach that centered on work design and promoting positive workplace conditions and relationships between management and employees. Enhanced employee engagement was seen as a positive outcome - productivity was not the primary goal. In the other case, a 'hard' approach concentrated on directly increasing employee effort to improve organizational performance. In the company using a soft approach high levels of engagement were reported, while in the other company high levels of employee disengagement were evident.

\section{DATA ANALYSIS AND INTERPRETATION}

It was important for this research to get information on demographic characteristics of the respondents that is information based on gender, age, experience, level and education in order to establish variations. Overall, there are 150 respondents $(75 \times 2)$ who contributedin survey on employee engagement. The research primarily focuses on MNC-based employees in the region of Delhi and NCR.

Table 1: HCL

\begin{tabular}{|l|l|c|c|}
\hline Variable & Category & Frequency & Percentage \\
\hline \multirow{2}{*}{ Gender } & Male & 50 & 66.7 \\
\cline { 2 - 4 } & Female & 25 & 33.3 \\
\hline \multirow{2}{*}{ Age } & $21-30$ & 53 & 70.7 \\
\cline { 2 - 4 } & $>30$ & 22 & 29.3 \\
\hline \multirow{3}{*}{ Experience } & $1-5$ & 36 & 48.0 \\
\cline { 2 - 4 } & $6-10$ & 33 & 44.0 \\
\cline { 2 - 4 } & $>10$ & 6 & 8.0 \\
\hline \multirow{2}{*}{ Level } & Trainee & 16 & 21.3 \\
\cline { 2 - 4 } & Executive & 59 & 78.7 \\
\hline \multirow{2}{*}{ Education } & Graduate & 56 & 74.7 \\
\cline { 2 - 4 } & Postgraduate & 19 & 25.3 \\
\hline
\end{tabular}

Of the 75respondents who participated in the survey, 33.3\% are female. More than two third of the respondents are between 21 and 30 years old. For work experience, $48 \%$ of the respondents have been employed in the IT sector for less than six years whereas $52 \%$ have been employed for more than six years. Executives comprised $78.7 \%$ of respondents while the remainingare trainees. Approximately three fourth of the respondents $74.7 \%$ have completed a graduation degree whereas $25.3 \%$ are postgraduates. 
Table 2: CSC

\begin{tabular}{|l|l|c|c|}
\hline Variable & \multicolumn{1}{|c|}{ Category } & Frequency & Percentage \\
\hline \multirow{2}{*}{ Gender } & Male & 68 & 90.7 \\
\cline { 2 - 4 } & Female & 7 & 9.3 \\
\hline \multirow{2}{*}{ Age } & $21-30$ & 41 & 54.7 \\
\cline { 2 - 4 } & $>30$ & 34 & 45.3 \\
\hline \multirow{3}{*}{ Experience } & $1-5$ & 31 & 41.3 \\
\cline { 2 - 4 } & $6-10$ & 26 & 34.7 \\
\cline { 2 - 4 } & $>10$ & 18 & 24 \\
\hline \multirow{2}{*}{ Level } & Trainee & 0 & 0 \\
\cline { 2 - 4 } & Executive & 75 & 100 \\
\hline \multirow{2}{*}{ Education } & Graduate & 31 & 41.3 \\
\cline { 2 - 4 } & Postgraduate & 44 & 58.7 \\
\hline
\end{tabular}

The sample consists of 75 respondents with $90.7 \%$ males showing the majority of the respondents and $9.3 \%$ females showing the minority of the respondents. For age, $54.7 \%$ of the respondents are less than thirty years old whereas $45.3 \%$ are more than thirty years old. The largest group of respondents $41.3 \%$ is working from 1-5 years, 6-10 yearsexperience respondents are $34.7 \%$ and $24 \%$ respondents have more than 10 years working experience in organization. For the level of the respondents $100 \%$ respondents are working asexecutive. The postgraduate degree holders are $58.7 \%$ whereas $41.3 \%$ respondents are bachelor degree holder.

\section{SUMMARY AND CONCLUSIONS}

It is concluded there is no universal definition on employee engagement however literature review is more or less consistent in its positive view of employee engagement and in that nature of engagement as a two-way interaction between employee and employer is emphasized in context of organizations. If every part of human resources is not addressed in appropriate manner, employees fail to fully engage themselves in their job in the response to such kind of mismanagement.The definitions which are used are mostly about employees' emotions, feelings and psychological attitude about the work and the company. Engaged employees will be fully involved in their work and will more behave in the interest of the company.Employee engagement helps to improve the culture of organization in terms of open communication, good rapport with all the levels of management and which will lead to increase productivity of the organization. It has emerged as a pivotal business driver for organizational success and improves employee loyalty to the organization.Studies have highlighted the importance of both organizational and individual factors in ensuring highly engaged employees. Employee Engagement is critical to business success is well understood by the Human Resource Professionals in the Information Technology Organizations. High level of engagement in domestic and global firms is supposed to have multiple enriching effects on an organization.

It promotes retention of talent, fosters customer loyalty and improves organizational performance and stakeholder value. In order to strive competitively in this period of globalization, managers must possess relevant competencies for effective implementation in the employee engagement policies and practices.The IT Management has realized that having a strong brand, new products, and new technology alone does not help them get the winning edge over competitors.Organizations need the committed participation of a good majority of people so that the effectiveness and efficiency of the organization could be enhanced.Attrition of human resource has become a big challenge for the HR leaders globally and one of the major KRA of their own performance matrix. Therefore, HR leaders work day-night to conduct various surveys and study developmental needs and reasons for attrition and keep designing various policies to 
retain the well trained human resource. In the above pursuits the HR leaders across the globe has arrived a conclusion that two variables' namely Employee Engagement and Employee Well-being are the solution to manage the Attrition. Despite tireless efforts by HR leaders across the globe, to design and implement employee engagement and wellbeing policies they have yet not been able to establish measurable link between Employee Well-being and Employee Engagement.Therefore by taking the engagement pulse of employees periodically throughout the year, HR leaders can develop and implement engagement initiatives and management strategies that take into account not only employees' present perceptions, but also their past experiences and future expectations. Hence to conclude, that raising and maintaining employee engagement lies in the hands of an organization and requires a perfect blend of time, effort, commitment and investment to craft a successful endeavor and to help them being productive employees.

\section{REFERENCES}

1. The State of the American Workplace: Employee Engagement Insights for U.S. Business Leaders report [Online].Available: http://www.gallup.com/strategicconsulting /163007/state-americanworkplace.aspx.

2. Kahn, W. A. (1990). Psychological Conditions of Personal Engagement and Disengagement at Work.Academy of Management Journal. 33, 692-724.

3. Buckingham, M. \& Coffman, C. (1999). First, break all the rules: What the world's greatest managers do differently. New York, NY: Simon \& Schuster.

4. Hay Group (2001). Engage employees and boost performance. www.haygroup.com/downloads/us/Engaged_Performance_120401.pdf.

5. Harter, J. K., Schmidt, F. L., \& Hayes, T. L. (2002), Business-unit-level relationship between employee satisfaction, employee engagement, and business outcomes: A meta- analysis. Journal of Applied Psychology, 87, 268-279.

6. Schaufeli, W., \& Bakker, A. (2003).Utrecht Work Engagement Scale, Utrecht University, Preliminary Manual, Ver. 1.

7. Robinson, D., Perryman, S., \&Hayday, S. (2004), The Drivers of Employee Engagement Report 408, Institute for Employment Studies, $U K$.

8. Measure, S. (2004), Significance of Employee Engagement. Compensation and Benefits Management.8,4,46-50.

9. Blizzard, R. (2004).'Engagement vs. satisfaction among hospital teams', Gallup Poll Tuesday Briefing, The Gallup Organisation, $9^{\text {th }}$ March.

10. Baumruk, R., \&Marusarz, T. (2004). Employee Engagement: Insights into Why It Matters and What You Can Do About It, Hewitt Associates LLC.

11. Development Dimensions International.(2005). (Predicting Employee Engagement MRKSRR12-1005 Development Dimensions International, Inc., MMV. [Online]Available: www.ddiworld.com (October 30, 2008).

12. Cropley, A. (2005). Employee Communications Surveys: an event or a culture?IABC International Conference, Washington, $D C$.

13. Seijts, Gerard H.; Crim, Dan (2006), What engages employees the most or The Ten C's of employee engagement. Ivey Business Journal, Mar/Apr2006, Vol. 70 Issue 4, p1-5, 6p.

14. Chartered Institute of Personnel and Development. (2006). Reflections on employee Engagement: Change agenda. CIPD: London. [Online] Available: http://www.cipd.co.uk/changeagendas (November10, 2008).

15. Mercer (2007).Exploring the Global Drivers of Employee Engagement, 
www.mercer.com/referencecontent.htm?idContent $=1281670$.

16. Penna (2007).Meaning at Work Research Report. [Online] Available: http:// www. epenna.com/newsopinion/research.aspx (November10, 2008).

17. Lockwood, Nancy $R$ (2007), Leveraging Employee Engagement for Competitive Advantage: HR's Strategic Role. HR Magazine, Mar 2007, Vol. 52 Issue 3, Special section p1-11, 11p.

18. Bakker, A. B., \&Demerouti, E. (2008).Towards a model of work engagement. Career Development International 13(3), 209223.

19. Gatenby, M., Rees, C., Soane, E., \& Truss, C. (2009).Employee engagement in context. London: Chartered Institute of Personnel and Development.

20. Demerouti, E., and Cropanzano, R. (2010). From thought to action: Employee work engagement and job performance. In A. B. Bakker and M. P. Leiter (Eds.), Work engagement: A handbook of essential theory and research, (pp. 147-163), Hove, East Sussex: Psychology Press.

21. Solomon Markos and M. SandhyaSridevi (2010), Employee Engagement: The Key to Improving Performance, International Journal of Business and Management, Vol. 5 (12), pp. 89-96.

22. Dr. YasminJanjhua (2011), Employee Engagement: A Study of HPSED Employees, International Journal of Research in IT \& Management, Vol 1 (6), pp. 74-89.

23. Kinjal Bhatt (2012), Employee Engagement: 'A Tool to Achieve Sustainable Growth -A Case Study Of GNFC', International Journal of Research in Management, Economics and Commerce, Vol 2(6), pp. 92 - 105.

24. Alfes, K., Truss, C., Soane, E., Rees, C. and Gatenby, M. (2013 - in press) 'Linking Perceived Supervisor Support, Perceived HRM Practices and Individual Performance: The Mediating Role of Employee Engagement'. Human Resource Management.

25. Jenkins, $S$ and Delbridge, $R$ (2013) Context matters: examining 'soft' and 'hard' approaches to employee engagement in two workplaces, International Journal of Human Resource Management, 24 (14), pp. 2670-91.

26. Swanlatha C and Sureshkrishna G (2013), "Employee engagement”, International Journal of Human Resource Management and Research (IJHRMR), ISSN 2249-6874, Vol. 3, No. 1, Mar, 1-6. 